IMECE2006-13537

\title{
A Collision Dynamics Model of a Multi-Level Train
}

\author{
Michelle Priante \\ David Tyrell \\ Volpe National Transportation Systems Center \\ US Department of Transportation \\ Cambridge, MA 02142 USA \\ Benjamin Perlman \\ Tufts University \\ Medford, MA USA
}

\section{ABSTRACT}

In train collisions, multi-level rail passenger vehicles can deform in modes that are different from the behavior of single level cars. The deformation in single level cars usually occurs at the front end during a collision. In one particular incident, a cab car buckled laterally near the back end of the car. The buckling of the car caused both lateral and vertical accelerations, which led to unanticipated injuries to the occupants. A three-dimensional collision dynamics model of a multi-level passenger train has been developed to study the influence of multi-level design parameters and possible train configuration variations on the reactions of a multi-level car in a collision.

This model can run multiple scenarios of a train collision. This paper investigates two hypotheses that could account for the unexpected mode of deformation. The first hypothesis emphasizes the non-symmetric resistance of a multi-level car to longitudinal loads. The structure is irregular since the stairwells, supports for tanks, and draglinks vary from side to side and end to end. Since one side is less strong, that side can crush more during a collision. The second hypothesis uses characteristics that are nearly symmetric on each side. Initial imperfections in train geometry induce eccentric loads on the vehicles. For both hypotheses, the deformation modes depend on the closing speed of the collision. When the characteristics are non-symmetric, and the load is applied in-line, two modes of deformation are seen. At low speeds, the couplers crush, and the cars saw-tooth buckle. At high speeds, the front end of the cab car crushes, and the cars remain in-line. If an offset load is applied, the back stairwell of the first coach car crushes unevenly, and the cars saw-tooth buckle. For the second hypothesis, the characteristics are symmetric. At low speeds,
\end{abstract}

the couplers crush, and the cars remain in-line. At higher speeds, the front end crushes, and the cars remain in-line. If an offset load is applied to a car with symmetric characteristics, the cars will saw-tooth buckle.

\section{INTRODUCTION}

The work for this paper was done under the Federal Railroad Administration's (FRA) Equipment Safety Research Program. The goal of the rail passenger equipment crashworthiness research conducted under this program was to propose strategies for improving occupant protection in train accidents. The effectiveness of conventional and alternative equipment is evaluated both with analyses and tests. The work described in this paper was included as part of a Master's Thesis [1].

The objective of this paper is to describe a collision dynamics model of a passenger train with multi-level cars. It is motivated by the structural behavior of a multi-level cars in a train collision occurred on April 23, 2002, in Placentia, CA.

In this train collision, a cab car-led commuter train was traveling down the tracks when a large freight train missed a signal and continued traveling down the same track toward the commuter train. The commuter train was able to stop. The freight train locomotive collided with the leading cab car end of the commuter train.

In the Placentia collision, the rear transition structure between the back mezzanine and the multi-level midsection of the cab car experiences the most significant damage. The cab car crushed and buckled vertically and laterally at the transition structure. In this collision very little crushing occurred at the front end of either the cab car or the front end of the locomotive. Research and accident data of single level rail 
equipment show that crush usually occurs at the train's front end [2].

The unexpected lateral motion experienced during the collision affected the occupant environment. In the interior of a train, the occupant environment should be designed such that the passengers are compartmentalized during a collision. This means that a passenger will not be thrown far within the car but will stay in a certain small area, such as between the seat and the seat in front. When the accelerations are not just in the longitudinal direction but also in the lateral and vertical directions, it is more difficult for an occupant to stay compartmentalized. In the Placentia collision, two fatalities occurred in the cab car. In both of the cases, the passengers were seated at tables before the collision, but they were thrown out of their seats during the collision. A collision dynamics model provides details on the gross motions of the car, including longitudinal and lateral accelerations. An occupant protection analysis uses these gross motions to determine the injury risk during a collision.

Two targets exist for this analysis. The model should be able to predict modes of deformation based upon different input parameters. The model should also provide details on the acceleration pulses in the cars, particularly the magnitude and timing of the lateral and longitudinal accelerations. An occupant protection analysis uses these gross motions to determine the injury risk during a collision.

A one-dimensional collision dynamics model was built to replicate the longitudinal force-crush behavior in the Placentia collision [3]. In this model, the lateral acceleration was represented as a pulse proportional to the longitudinal acceleration. With these components as inputs, an occupant protection analysis explained how the injuries could have occurred in the interior.

This paper presents a three-dimensional version of a train with multi-level cars. The three-dimensional version of the model gives acceleration-time histories, particularly in the lateral direction. This paper explores two alternate hypotheses for the lateral buckling in the back stairwell. The first hypothesis is that the stairwells are non-symmetrically strong due to structural asymmetries. For this hypothesis, a symmetric load is applied to the front of the train. When a force is applied, the characteristic in the back stairwell is weak enough that it begins crushing there. Then, due to asymmetry in the forcecrush characteristics, one side of the stairwell crushed more than the opposite stairwell, leading to lateral buckling.

The second hypothesis is that the stairwells are symmetrically, or nearly symmetrically strong, and the buckling is a result of out-of-line loading. A second set of force-crush characteristics indicated that although asymmetries exist in the structure, the force-crush curves are almost symmetric when the structure is loaded in-line. If the stairwells are symmetrically strong, then offset loading is necessary for buckling behavior.

The paper starts with background information on the collision, the structure of the multi-level car, collision dynamics modeling, and the strategy for modeling a multi-level train.

The model was developed in two phases. The basic structural behavior was established with a representation of a single car. It was duplicated and connected to additional cars and a locomotive to create a model of a typical commuter train. Table 1 contains information about the models discussed in this paper, their goals, and the important modeling features they include. The important features of the cab car are the truck and track connections, front-end mechanism, force-crush characteristics, stairwell characteristics, and initial conditions. The goal of the one car model is, most importantly, to create a functioning model. This model should have reasonable collision dynamics. Appropriate degrees of freedom for the model include pitch, yaw, and roll, as well as buckling and derailment under high lateral forces. The model should allow for the mode of deformation from the Placentia collision.

The one car model has a quasi-static loading condition, which is used to compare results with a finite element model. In the quasi-static model, the back of the car is restricted longitudinally. The wall has a velocity profile that gradually increases from zero to top speed.

\section{Table 1. Modeling strategy}

\begin{tabular}{|c|c|c|}
\hline & Goal of model & $\begin{array}{l}\text { Important Modeling } \\
\text { Features }\end{array}$ \\
\hline $\begin{array}{l}\text { One } \\
\text { Car }\end{array}$ & $\begin{array}{ll}\text { - } & \text { Functioning model } \\
\text { - } & \text { Reasonable collision } \\
\text { dynamics } \\
\text { - } & \text { Appropriate degrees of } \\
\text { freedom } \\
\text { - } \\
\text { Allow for specific modes } \\
\text { of deformation }\end{array}$ & $\begin{array}{ll}\text { - } & \text { Truck and track } \\
& \text { connection } \\
\text { - } & \text { Front end } \\
\text { - } & \text { Transition } \\
\text { structure } \\
\text { characteristics } \\
\text { - } & \text { Initial conditions } \\
\end{array}$ \\
\hline $\begin{array}{l}\text { Full } \\
\text { Train }\end{array}$ & 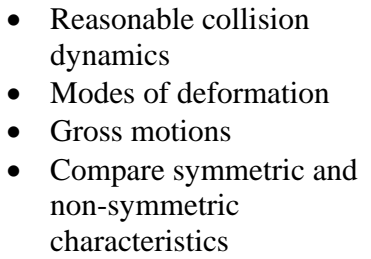 & $\begin{array}{l}\text { - Second coach car } \\
\text { - Locomotive } \\
\text { - } \text { Truck characteristics } \\
\text { - } \text { Couplers }\end{array}$ \\
\hline
\end{tabular}

The full train model includes the leading cab car, two coach cars, and a trailing locomotive. The train collides with a fixed wall. The goals of this model are to have reasonable collision dynamics and show modes of deformation. Important outputs from this model are the gross motions of the cars. The nonsymmetric and symmetric characteristics are compared in the full train model. Important features of the full train model are the second coach car and the locomotive, the simplified truck characteristics, and the couplers between the cars.

\section{BACKGROUND INFORMATION}

\section{The Placentia Collision}

The National Transportation Safety Board (NTSB) report gives the details of a collision in Placentia, CA [4]. On April 23, 2002, a moving freight train hit a standing cab led passenger train head on. Single level cars in head-on collisions typically crush at the front end of the train [5]. This crushing may then lead to override of the cab car, derailment of the trucks, or saw-tooth buckling between cars. In this crash, however, the cab car buckled at the back stairwell, crushing there instead of at the front of the car. Figure 1 shows the buckled back end of the cab car. 


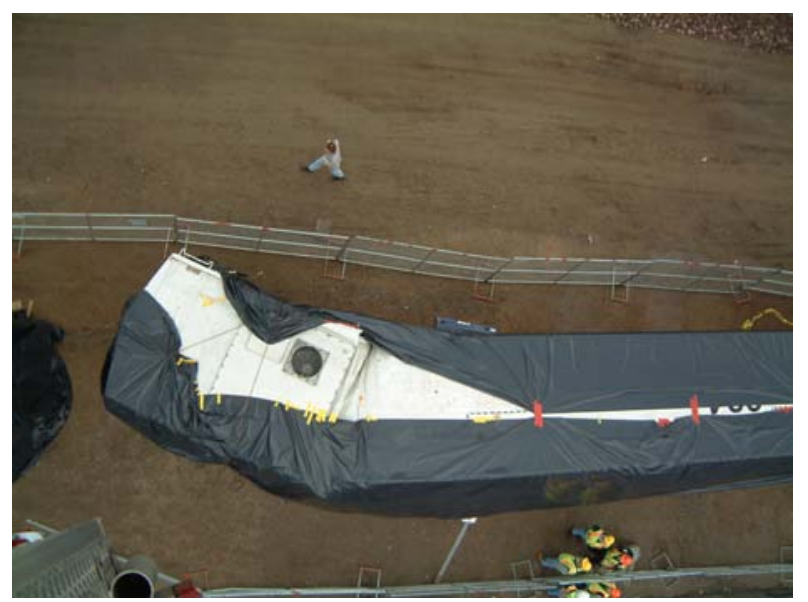

Figure 1. Overhead view of the B-end (back end) of the cab car

The commuter train had a leading multi-level cab car, two multi-level coach cars, and a trailing locomotive. The freight train BNSF 5340 consisted of three leading locomotives and 27 loaded multi-platform intermodal freight cars. The passenger train was initially standing. The freight train, though decelerating, hit the passenger car with an initial velocity of approximately $23 \mathrm{mph}$.

Minimal crushing occurred in the front end of the cab car. Little damage also occurred on the front end of the freight train locomotive.

Two fatalities resulted from this collision. Both of the fatalities were passengers seated at workstation tables. These passengers impacted the tables and were thrown into the aisles. The lateral buckling of the car likely contributed to the noncompartmentalization of the passengers. In addition to lateral buckling, some vertical movement occurred between the middle part of the car and the car end.

\section{Structure of a Multi-level Car}

In collisions, the structural response of a multi-level car is different from the response of a single level car. Typically in a single level car, the underframe is straight. Three strong longitudinal members, the center sill and two side sills, support the load. While the multi-level structure has these same longitudinal members, they are not straight along the underframe of the car.

As seen in the Figure 2, multi-level cars have two sets of stairwells, which connect the lower level to the mezzanine levels and the upper level. The mezzanine levels are located at the ends of the cars over the trucks.

The coach and cab cars are similar in structure, except the cab car has an operator's compartment at the front end. In the coach car, the front mezzanine level has seating for passengers. In the cab car, this front mezzanine level is reserved entirely for the operator and operating equipment. The operator's compartment includes braking equipment and electrical equipment. This equipment adds about 3,000 lb to the weight of the cab car. A cab car weighs approximately 140,000 lbs while the coach car weighs approximately $137,000 \mathrm{lbs}$. These values include the trucks, which weigh 12,000 lbs each.

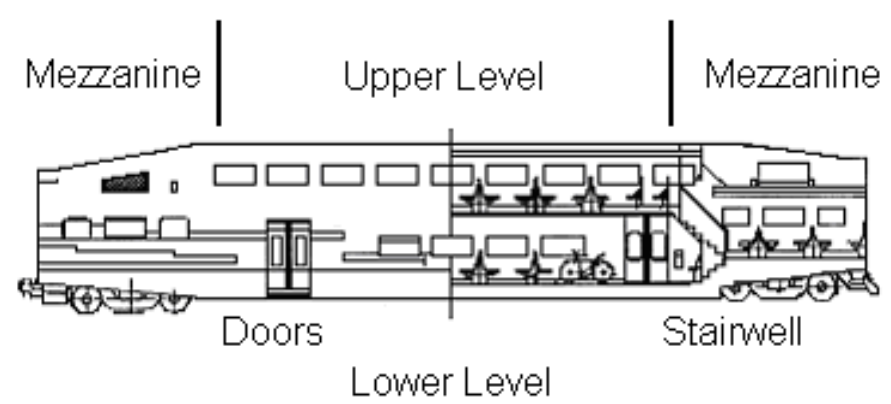

Figure 2. Schematic of multi-level car

A Federal regulation requires that the buff stops support a longitudinal static compressive load of 800 kips without permanent deformation. In a typical single level car, the underframe, which includes the center and side sills, supports the majority of this load. Figure 3 shows the location of this force on the car body.

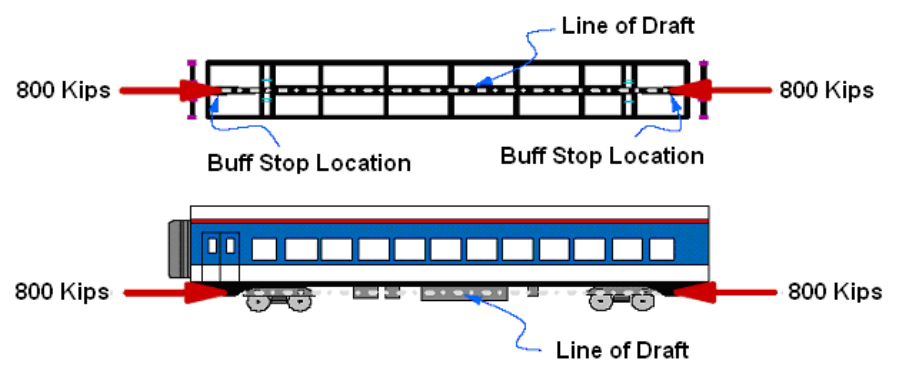

Figure 3. Force applied along the line of draft at the buff stops, single level car shown

As a result of the multiple levels of the car, the car's underframe is not straight. The frame is at one height for the mezzanine level and a lower height for the lower level. Figure 4 shows the car's underframe, which has two transition structures that connect the mezzanine levels to the lower level. In the multi-level cars, the 800 kip static load is supported mainly by the underframe, which includes the goosenecks. The load is also transferred through the sides of the car, the roof structure, and the floor of the upper level.

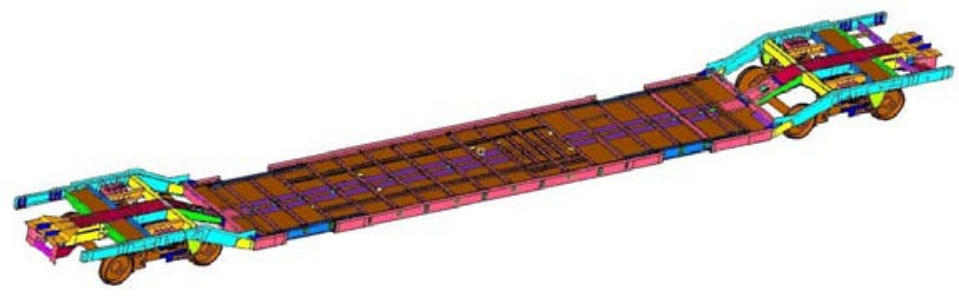

Figure 4. Underframe of a multi-level car

While most single level cars are uniform in strength between the buff stops, significant variations exist in stiffness from one longitudinal segment to another in the multi-level cars.

\section{Collision Dynamics Modeling}

This paper describes a collision dynamics model. A collision dynamics model is a lumped parameter model, where a collection of rigid bodies are connected by springs and are constrained to move in prescribed directions [6]. 
A collision dynamics model allows for exploration of different scenarios and configurations. For example, the model provides data for running the train at different speed or with a different force crush characteristic at the front end. It shows the coupling between the cars, the forces between the cars and the accelerations of the cars. The one car model runs in a carriage return and the four-car model runs in less than a minute.

Collisions dynamics models are useful in predicting the outcomes of full-scale tests. Reference [7] includes a comparison of one- and two-car collision dynamics models to test results for conventional rail vehicles. This modeling approach has been extended to test predictions for collision energy management vehicles with equally reliable results [8].

The multi-level car model described in this paper uses similar modeling techniques for the car-to-wall interaction and force/crush behavior. The three-dimensional rigid body motion and car-to-car interactions, however, are somewhat different in the multi-level model.

A finite element model of a multi-level car was built concurrently with the collision dynamics model. The forcecrush characteristics for the transitions structure, which are discussed later in this paper, come from the finite element model [9].

\section{ANALYSIS STRATEGY}

The model for the multi-level train is built one car at a time. The finite element model provides an initial reference. In addition, the behavior of the car in the Placentia collision is a basis for understanding the crush in a multi-level car.

The one-car model is the baseline model for the rest of the cars in the train. The essential parts to calibrate are the front end, the trucks and the transition structure force-crush characteristics. Numerous spring constants, friction coefficients, and joint types are also adjusted in the one-car model.

The one-car model checks the collision dynamics model against the finite element model. In a quasi-static loading condition, the back of the car is fixed, and the wall has a prescribed velocity. This version of the one-car model shows that the collision dynamics car has the same mode of deformation as the finite element car. The finite element model results provide a basis for calibrating the collision dynamics model. The collision dynamics model behaves as expected under these loading conditions.

The full train model replicates the train in the collision in Placentia, CA. The train has a cab car, two coach cars, and a locomotive. The cab car and first coach car come from the twocar model. A single mass represents the second coach car. No separate truck masses are in the second coach car, but there are characteristics allowing the truck to laterally derail. The locomotive is represented the same as the second coach car, with a heavier mass. This full train model is manipulated to show the behavior of the car in different scenarios.

Different loading cases are used to test the hypotheses. Inline and out-of-line loading is applied to both structures, nonsymmetric and symmetric.

\section{One-Car Model}

The one-car model is the cab car, a track, and a wall. The model has five important features: transition structure characteristics, car mass, front-end mechanisms, truck and track connections, and initial conditions. The transition structure characteristics describe the force-crush characteristics that represent the structure at the goosenecks and the stairwell that transitions from the mezzanine to the bi-level midsection. Two sets of characteristics are provided, non-symmetric characteristics and symmetric characteristics. The largest difference between the cab car and the coach car is the operator's cabin. The operator's cab is on the mezzanine level on the A-end of the cab car. This area holds equipment for braking and electrical wiring. The equipment in the operator's compartment adds to the weight of the cab car. In a coach car, there is seating on the mezzanine levels of the cars.

The trucks connect to the track, which is grounded. The connections allow the trucks to move along the track under normal longitudinal forces. Under high lateral force, the trucks can derail and move laterally. The suspension system connects the truck to the car body. A separate system exists for each truck. The suspension allows the truck and carbody to yaw, pitch, and roll separately while keeping the truck connected to the carbody.

The first car is composed of five main masses, along with two other masses that assist with the front-end mechanism. The carbody is composed of three masses, which represent the back mezzanine, the bi-level midsection, and the front mezzanine. In between the sections are force-crush characteristics in the longitudinal direction. There are also forces with spring constants in the lateral direction. Figure 5 shows the masses.

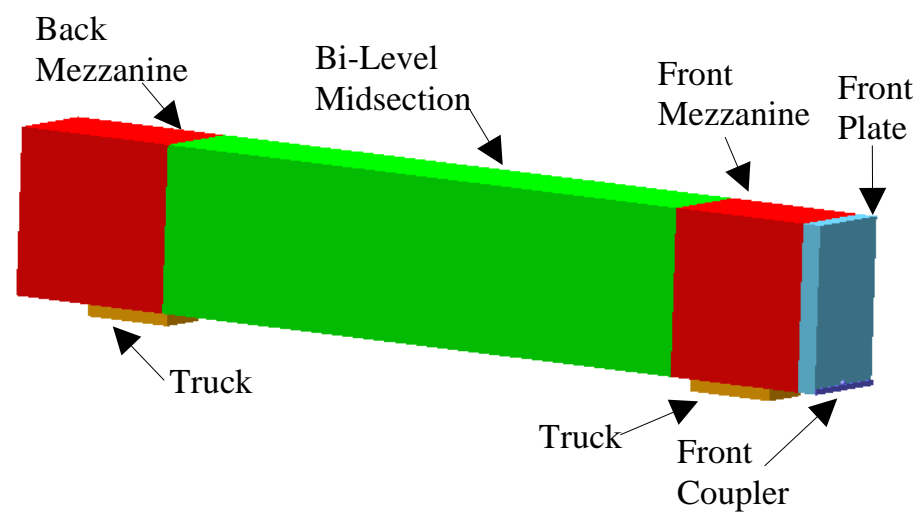

Figure 5. Layout of the masses in the cab car

The front end of the car has coupler and front end characteristics that allow forces to be transmitted through the car while the cars rotates in any direction. Figure 6 shows a schematic. The coupler box is fixed to the coupler sphere. There is a contact force between the coupler sphere and the wall that will apply no matter the rotation of the car. The coupler attaches to the front end box with a non-linear force and a translational joint. There is a contact characteristic between the front end sphere and the wall. The front end sphere attached to the car body with a non-linear spring and a translational joint. 


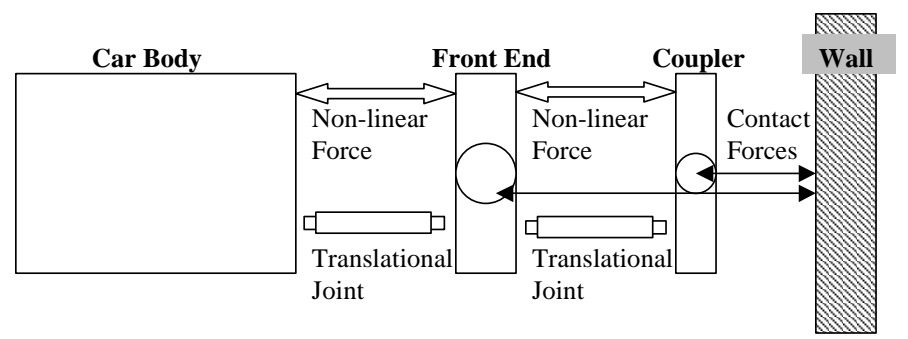

Figure 6. Constraints and Forces in the Front End Mechanism, Top View Schematic

On the front end of the car, there are rigid bodies with negligible mass. The sequence of events in the collision dynamics model, shown in Figure 7, begins when the coupler sphere contacts the wall. The contact force between the wall and the sphere is a linear spring with damping.

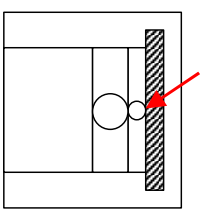

Step 1:

Coupler sphere Coupler crushes contacts wall

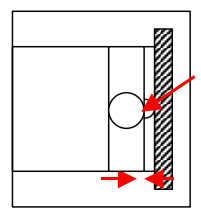

Step 2:

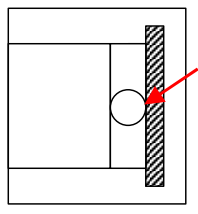

Step 3:

Front end sphere contacts wall

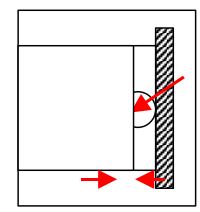

Step 4:

Front end

crushes
Figure 7. Sequence of Events for the Front End Mechanism

In the next step in the sequence the coupler crushes. The coupler sphere and the coupler box are both massless and are joined by a fixed joint, which allows no rotation or movement between the part.The translational joint constrains the coupler box so that it can only move along the $\mathrm{x}$-axis of the front plate.

When the coupler has been pushed back, the front end sphere contacts the wall. The mechanism here is similar to the mechanism used for the coupler. The contact force between the wall and the front end sphere is a linear spring with damping.

In the final step of the sequence, the front end pushes into the main car body. The front box sphere is connected to the front plate by a fixed joint. This joint does not allow movement or rotation between the parts. Between the front end plate and the front section box, a force vector exists. A nonlinear forcecrush characteristic governs movement along the $\mathrm{x}$-axis. The front end is designed to represent the front end of a conventional car during a collision. Figure 8 shows the forcecrush characteristic between the front end and the car body.

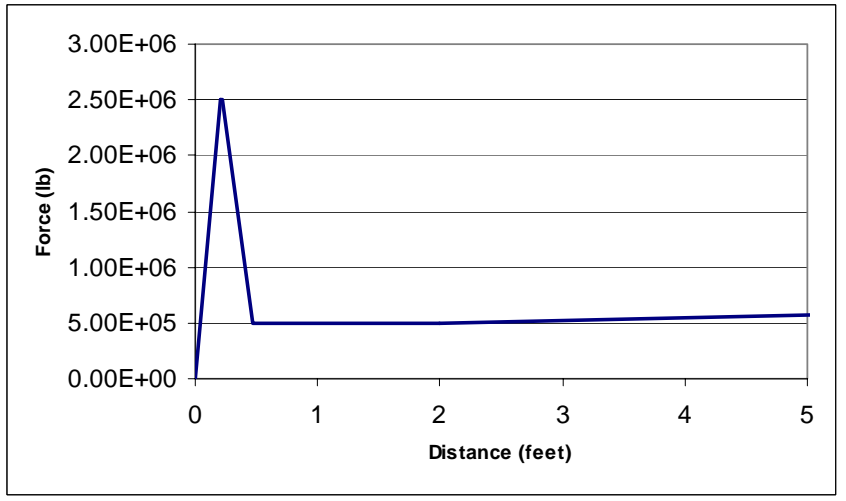

Figure 8. Force-Crush Characteristic for the Front End
The mass of the cab car, less the weight of the two trucks, is split between the three boxes. The entire car is 85 feet long, and the end sections are 15.5 feet long each. Each section has a concentrated mass appropriate for its length. The mass of each part is located 1.5 feet above the bottom of the car. The inertia of each section of the car is calculated using the mass of each section.

The three sections are held in the same vertical plane with two planar joints. These joints allow the sections to move out of a global vertical plane, but they stay in an vertical plane relative to each other. The entire car can pitch or roll, but the individual sections of the cars cannot. The planar joints allow the sections to yaw relative to one another. Since there are three sections and two trucks, static equilibrium is difficult to satisfy if the sections are not locked in the same plane.

\section{Structure: Symmetric versus Non-Symmetric}

Two versions of the transition structure characteristics are used in this model. The first group of transition structure characteristics assumes that the sides of the structure are nonsymmetric. The second set of characteristics is nearly symmetric left to right. These force-crush characteristics are based on finite element models of the structure.

In the model, the car is broken into three sections plus two trucks. The three sections represent the front mezzanine, the bilevel middle section, and the back mezzanine. While each of these pieces is rigid, they are attached together with threedimensional force vectors at two locations. Figure 9 shows a top view schematic, not drawn to scale. The location of the transition area defines the geometry of the boxes. The boxes all have a height of 15 feet and a width of 9 feet. The overall length of the car is 85 feet.

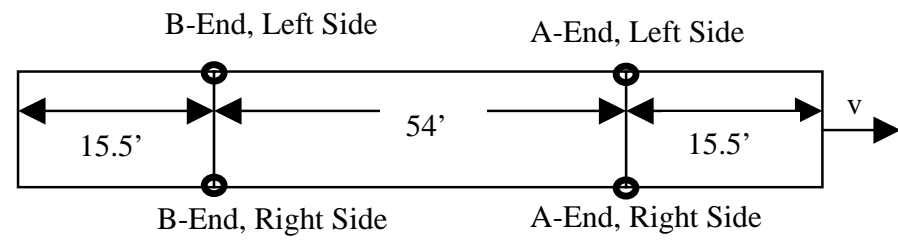

Figure 9. Top view schematic of multi-level car, not to scale

The force vectors are located at the outer sides of the car. The force vectors in the longitudinal direction are nonlinear springs. The nonlinear force-crush characteristics used to represent the transition structure come from the finite element one car quasi-static model of a multi-level car. The force crush characteristics are a compilation of the forces on the left side or the right side of the car.

\section{Non-Symmetric Transition Structure Characteristics}

Figure 10 shows the non-symmetric transition structure characteristics. The force-crush characteristics are approximations of a curve taken from a finite element model. The transition structure characteristics are similar for the first 0.2 feet. At 0.2 feet, the strong side has a slightly higher force than the weak side. After 0.2 feet, the force on the weak side is lower, and the force on the strong side increases. The difference in force levels allows one side of the stairwell to crush more than the other. 


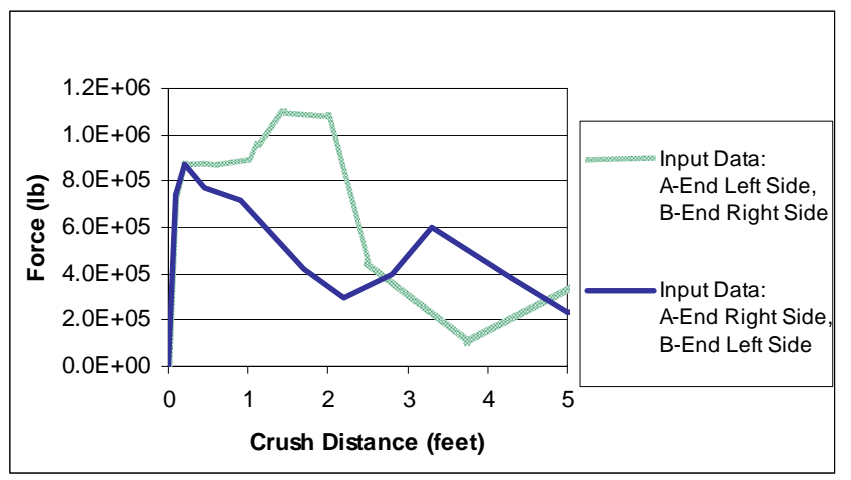

Figure 10. Non-symmetric transition structure characteristics for A-end and B-end

\section{Symmetric Transition Structure Characteristics}

Figure 11 shows the symmetric stairwell characteristics. The force-crush characteristics are the approximations of output data from the finite element model. For the A-end of the car, the left and right side behave similarly enough for one characteristic to represent both sides. For the B-end of the car, the characteristics are slightly different. The left side of the Bend is slightly stronger than the right side.

In the lateral direction of the force vectors, a linear spring exists with a constant of $1 \times 10^{6} \mathrm{lb} / \mathrm{ft}$. The force vectors do not have a constraint in the verticle direction, since the sections are held in the same verticle plane relative to each other.

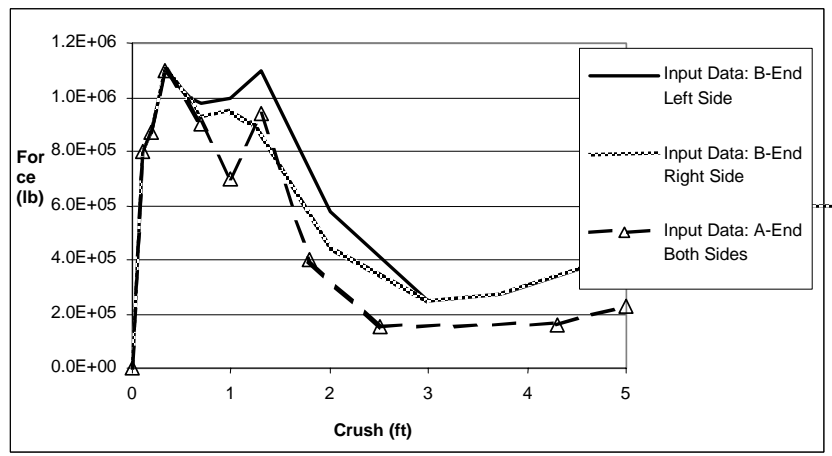

Figure 11. Symmetric force-crush characteristics for the transition structure

\section{Loading: In-Line versus. Out-of-Line}

Two loading cases exist for the full train model. For each case, the train has an initial speed and impacts a fixed wall. In the in-line loading case, the front-end forces and the coupler forces are in-line with the centerline of the car. In the out-ofline loading scenario, the coupler between the cab car and the first coach car is rotated 2.5 degrees initially. Everything else is in-line.

\section{Full Train Model}

The full train model has the same types and number of cars as the passenger train that was involved in the collision in Placentia, CA. The passenger train consists of a leading cab car, two coach cars, and a trailing locomotive. In the accident, derailment occurred in the first two cars only. The trailing cars remained in-line with no crushing. The model runs for 1 second of simulation time. It takes under 5 minutes to run.
The first coach car is nearly identical to the cab car. Truck and track connections, couplers on the front and back end, and three separate sections represent the two mezzanines and the bilevel mid-section.

There is expected to be negligible out-of-line movement in the last two cars. Since little movement is expected, the last two cars are modeled as two-dimensional objects, with full longitudinal movement and limited lateral movement. The cars are represented as single masses.

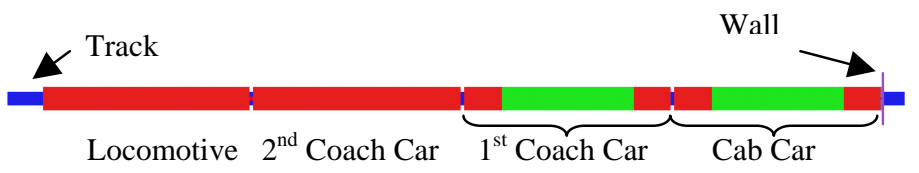

Figure 12. Layout of the passenger train

The second coach car model is simpler than the first two cars in the consist. In the collision in Placentia, CA, the third car did not derail or crush. The car in this model has the appropriate degrees of freedom to enable it to derail under high lateral forces.

A single mass represents the locomotive. Constraints on the locomotive are similar to the second coach car. A planar joint holds the locomotive in the vertical plane. Vertical movement is restricted. Two vector forces exist at the locations of the trucks. The vector forces only act in the lateral direction. The spring constant for the locomotive is higher than the other cars, since the locomotive is substantially heavier than the passenger cars. At a lateral force of half the weight of the locomotive, each truck can move 0.2 feet laterally. Once the force reaches $132,500 \mathrm{lbs}$, half the weight of the locomotive, in the lateral direction, the force remains at that level and does not increase.

\section{RESULTS}

\section{Comparison to Finite Element Model in Quasi-Static Case}

A quasi-static loading case is useful for determining full force-crush behavior. This model demonstrates the structural response of the car to quasi-static loading. A quasi-static load starts at zero and slowly increases to some value. The quasistatic load does not have the dynamic effects seen in a model with an initially high velocity. The quasi-static load also has more capabilities than the static load. The full force-crush characteristic is best achieved by using the quasi-static loading condition.

For the quasi-static one-car model, the wall has a prescribed velocity, in the form of a cosine wave. The velocity profiles are intended to simulate a quasi-static test on the front end of the car.

Constraints on the collision dynamics model allow for comparison with the finite element model. Results include both the non-symmetric and symmetric transition structure characteristics. The results also include the amount of crush in each area at different speeds and the amount of crush at each area when the back transition structure is weaker.

The non-symmetric transition structure characteristics are used for these first results. Figure 13 shows the model behavior for various velocity profiles. The top speed refers to the top speed that the wall reaches during the simulation. When the 
transition structure characteristics are non-symmetric, the front end buckles. The front transition structure buckles more at faster wall speeds.

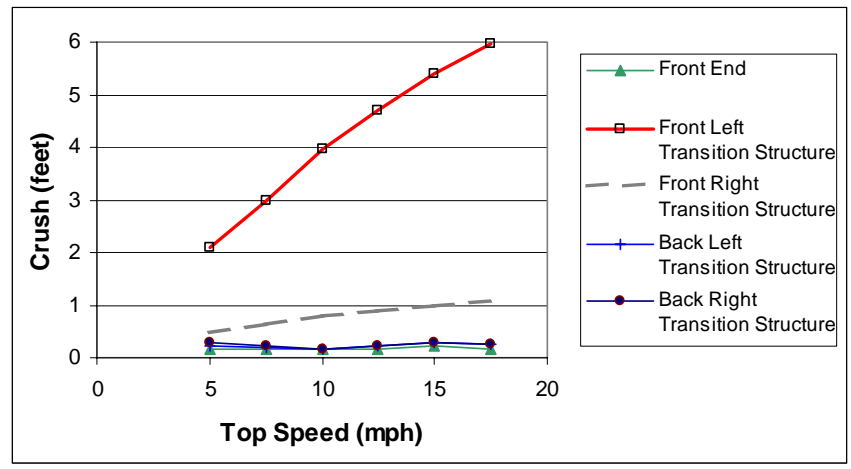

Figure 13. One-car quasi-static model, wall speed variations, non-symmetric case

A second result from the quasi-static model is the behavior of the model when the back transition structure is weaker. The model has non-symmetric transition structure characteristics for these results. For a weaker back transition structure, the crush distance values stay the same while the force values are reduced by a percentage. Figure 14 shows the crush distances at the front end and both sides of the front and back transition structures. In these cases, the wall was running with a top speed of $15 \mathrm{mph}$, using a quasi-static velocity-time condition.

The model has two distinct modes of deformation depending on the strength of the back transition structure. When the back transition structure is normal strength, the front transition structure crushes more on the weaker left side. The front end and back transition structures crush minimally. The left side of the transition structure, which has a weaker force/crush characteristic, crushes approximately 4 feet more than the right side. When the back transition structure is 20 percent weaker, both the front and the back transition structures buckle. When the back transition structure is 25 percent weaker than the front transition structure, the back transition structure crushed and buckles, while the front transition structure and front end remain intact. This case demonstrates the degrees of freedom and the modes of deformation allowed by the model. Figure 15 shows these modes of deformation.

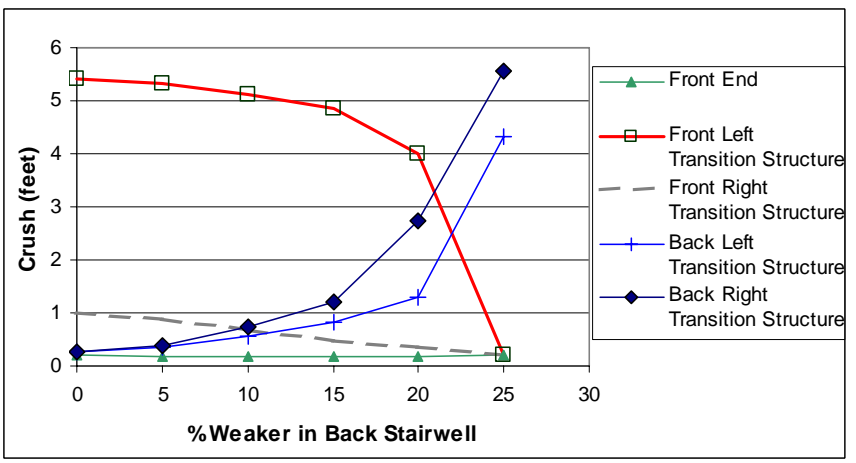

Figure 14. Distribution of crush for different force-crush characteristics in the back transition structure, nonsymmetric case, $15 \mathrm{mph}$ initial velocity
Percent weaker in Back Stairwell:

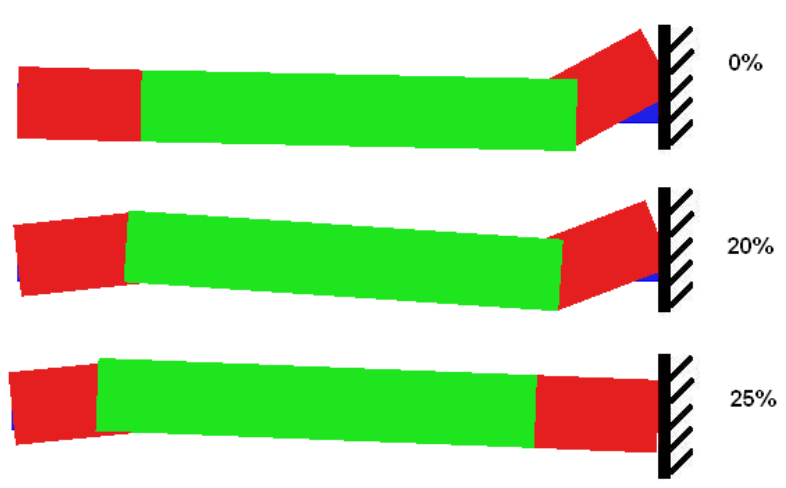

Figure 15. Modes of deformation in the quasi-static model, non-symmetric characteristics

\section{Full Train Cases}

\section{Non-Symmetric Transition Structure Characteristics}

Figure 16 shows the modes of deformation of the train over a range of speeds. The results are for non-symmetric characteristics. At low speeds, $5 \mathrm{mph}$, the collision remains inline, and the couplers absorb the energy. At $10 \mathrm{mph}$, some sawtooth buckling occurs between the cars. At $10 \mathrm{mph}$, the front transition structure of the cab car crushes about a foot in-line. At 12.5 and $15 \mathrm{mph}$, when the cars saw-tooth buckle, high lateral forces exist. In the cab car and the two coach cars, the force in the trucks reaches $70,000 \mathrm{lbs}$, so derailment is anticipated. At these speeds, between a half of a foot to a foot of crush exists in the transition structures of the cab car. At higher speeds, $20 \mathrm{mph}$ and over, the front end of the car crushes, and the collision remains in-line.

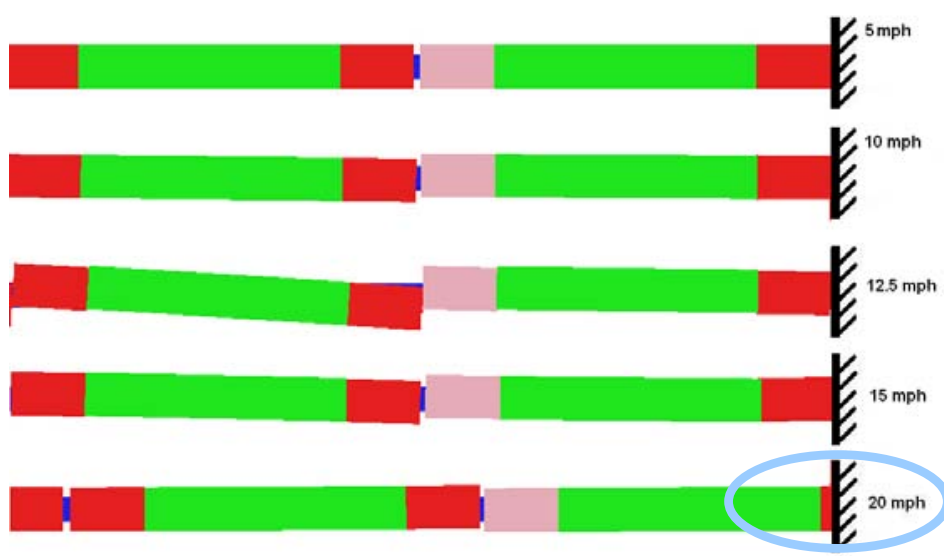

Figure 16. Modes of deformation of the full train model at different speeds, non-symmetric characteristics

The force transmits longitudinally through the consist during a collision. The wave of force passes through the front coupler of the cab, through the first car to the second coupler, through the first coach car to the third coupler, to the forth coupler. Figure 17 shows the force time histories for the couplers and the front end. The front end sees a force of 2.5 million lbs at 0.025 seconds. At 0.04 seconds, the second coupler at the rear of the cab car sees a low force, corresponding to the draft gear. The draft gear loading is followed by the coupler loading and a sharp increase in force. When this force reaches 1 million lbs, the coupler breaks, and 
the force remains at that level. At 0.1 seconds, the third coupler, at the rear of the first coach car, sees a similar force pattern as the previous coupler. The draft gear crushes at a low force, then the coupler loads. When the force in the coupler reaches 1 million lbs, the force remains constant.

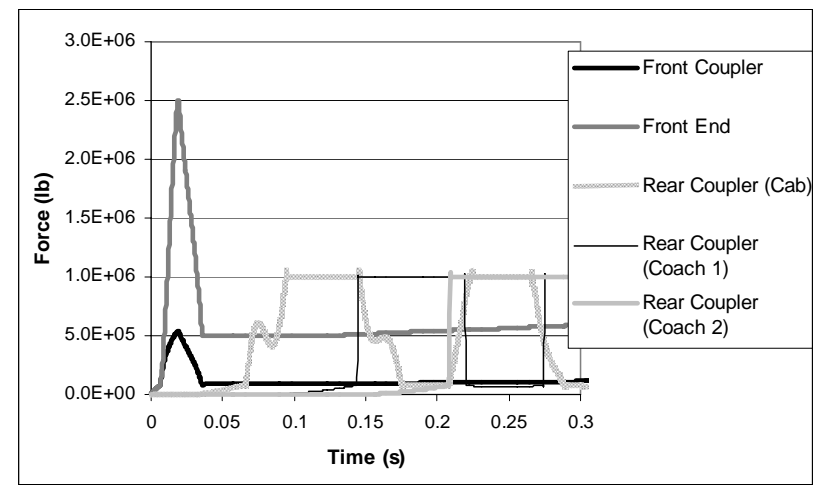

Figure 17. Force-time history for a 20-mph collision

The velocity traces for the train at $20 \mathrm{mph}$ are exhibited in Figure 18. In this case, the train crushes at the front end. The cab car goes from full speed to zero in about 1 second. The cars slow down in order, the cab decelerates to $10 \mathrm{mph}$, and then the first coach car decelerates to about $10 \mathrm{mph}$. The second coach car decelerates steadily to $10 \mathrm{mph}$. The cars then all slow down to $0 \mathrm{mph}$ by 1 second.

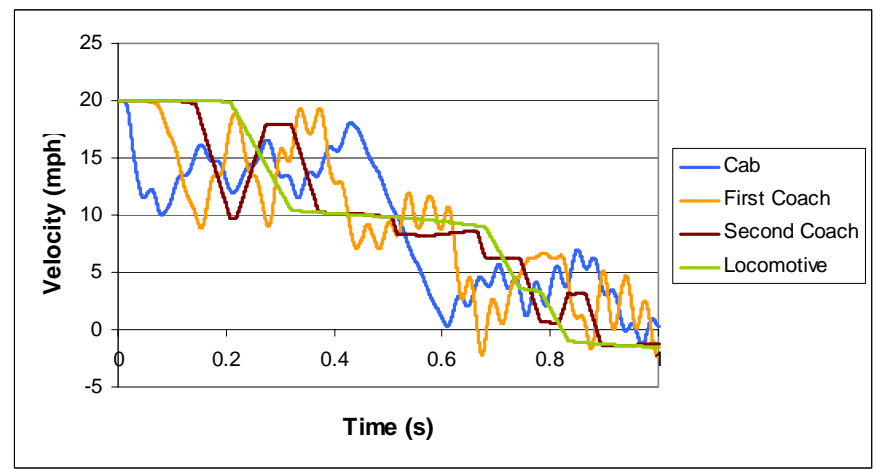

Figure 18. Velocity traces for the center of masses of the cars in the longitudinal direction

The accelerations in the first and second car are of particular interest. In the collision in Placentia, CA, buckling at the back transition structure of the cab car produced high longitudinal and lateral accelerations. The accelerations shown here are from the center of mass of the cab car and the first coach car. For this scenario, lateral accelerations are low, since negligible lateral movement occurs. Figure 19 shows the accelerations experienced by the center of mass of the car for the coach car and the cab car. The cab and the first coach car have similar high acceleration pulses in the longitudinal direction. The timing of the pulses is consistent with a collision where the cars experience separate collisions. The lateral decelerations are negligible for this case.
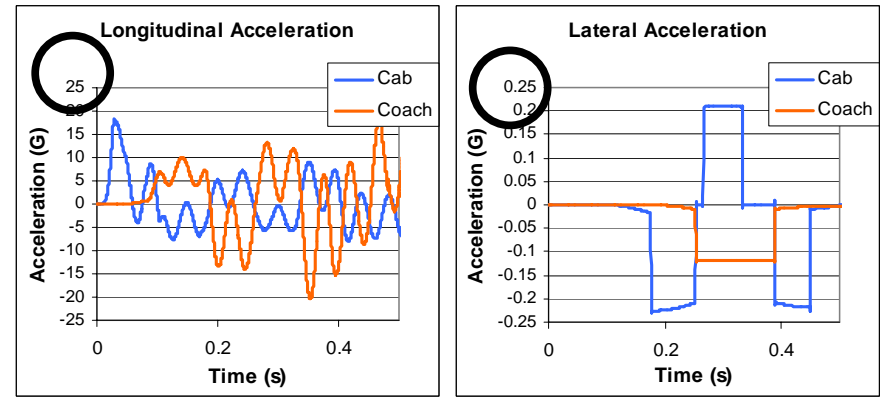

Figure 19. Acceleration traces in the longitudinal and lateral directions for a 20-mph collision. Note different scales.

A typical measure for injury is the secondary impact velocity (SIV). The SIV is the speed at which the passenger impacts the interior of the train. If a seat is 2 feet in front of the passenger in the cab car, then the anticipated SIV is approximately $10 \mathrm{mph}$. As general guidelines, SIVs less than $20 \mathrm{mph}$ are considered survivable [5]. In this collision, the speed is $20 \mathrm{mph}$, so most likely there will not be severe injuries due to SIV. The velocity is plotted against the displacement. The SIV is the value of the velocity at a prescribed distance, typically 2 feet. This represents a typical seat pitch in commuter trains. Figure 20 shows the SIV for a $20 \mathrm{mph}$ collision. AT $20 \mathrm{mph}$ the SIV is well under the survivable limit.

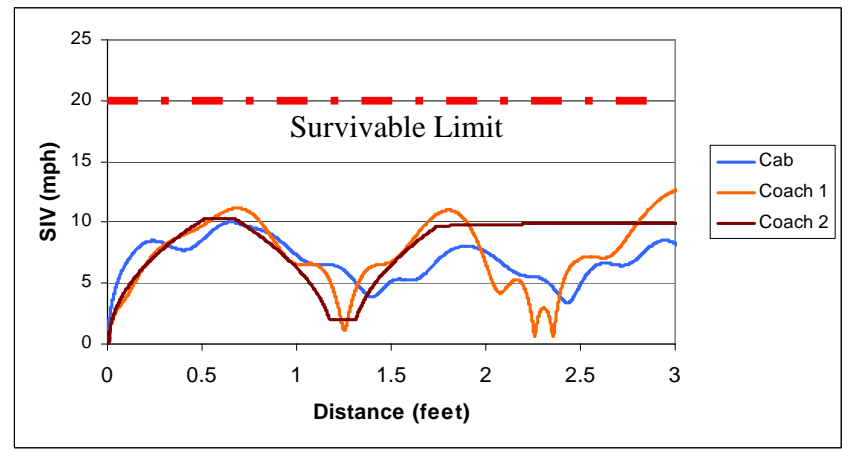

Figure 20. Secondary impact velocity for a $20 \mathrm{mph}$ collision

Figure 21 shows the SIV for an initial velocity of $15 \mathrm{mph}$. In the 15-mph case, the front end does not crush. Instead of the front end crushing, the couplers crush, and the cars saw-tooth buckle. Since the cars each decelerate to zero in their own separate collision, the accelerations are more severe. For this particular mode of deformation, the occupant environment is more severe than the 20 -mph case, despite the lower initial velocity. 


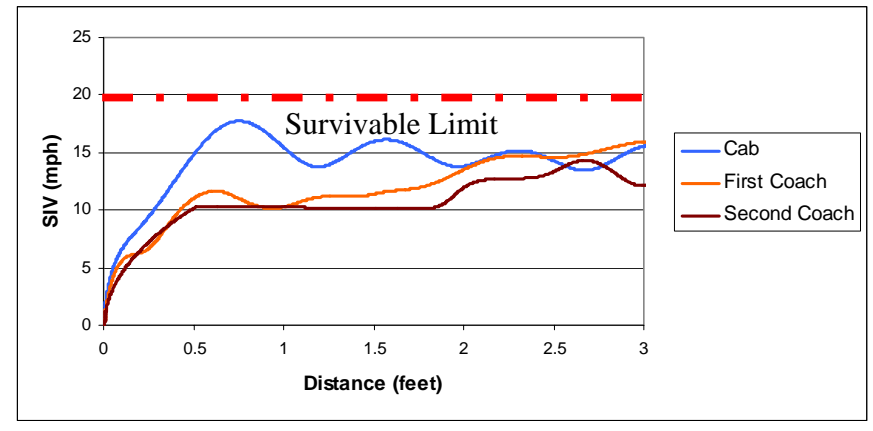

Figure 21. SIV for a $15 \mathrm{mph}$ collision

Figure 22 shows out-of-line loading cases for the nonsymmetric structure. The model runs at $15 \mathrm{mph}$ for these cases. At 0.6 seconds, the SIV in the cab car is higher than the collision speed due to rebound. In the top picture, the coupler between the cab and the coach car is rotated counter clockwise 2.5 degrees about the vertical axis. This initial offset causes the cars to saw-tooth buckle. In addition, the back transition structure of the first coach car buckles. The right side of the transition structure crushes 1.2 feet, and the left side crushes 0.6 feet at the transition structure. The front car crushes approximately half a foot at each characteristic, front and back, left and right. The coach car also crushes about half a foot at the front transition structure. The front ends of the cars do not crush. In addition, there are high lateral forces in the trucks. All of the trucks, including the trucks in the locomotive, hit the lateral force limit for derailment.

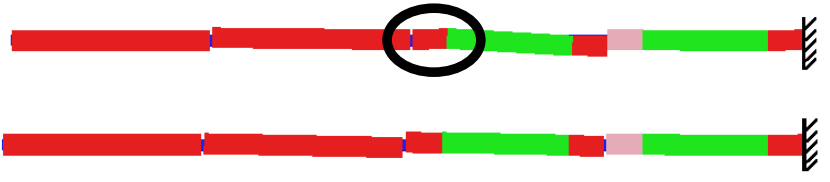

Figure 22. Out-of-line loading condition (top), in-line loading condition (bottom)

\section{Symmetric Transition Structure Characteristics}

As previously mentioned, two hypotheses explain the lateral buckling in the back transition structure during the collision in Placentia, CA. The two hypotheses relate to the structure transitioning between the mezzanine and the bi-level midsection. The structure, while non-symmetric due to the stairwell and other factors, had been strengthened to account for the irregular structure. The first hypothesis, previously discussed, is that the transition structure is irregularly strong and will crush unevenly during in-line loading. It has been shown in the results that irregular structure leads to saw-tooth buckling at low speeds.

The second hypothesis is that the transition structure, while physically irregular, has been strengthened so that the sides are symmetrically strong. If the structure is symmetrically strong, then off-axis loading may have caused the buckling. An out-ofline coupler initiates the out-of-line load.

The results presented here use the symmetric characteristics. Initially the loading is in-line. As expected, the in-line loading causes the car to fail at the front end of the train, which is typical for cab leading consists. In a second set of results, the load is offset. Rotating the coupler to an initial offset causes offset loading.
When a symmetric structure and in-line loading occur, the train does not laterally buckle at the transition structure or sawtooth buckle at the couplers. Instead, the cars remain in-line. For lower speeds, under $15 \mathrm{mph}$, the train crushes only at the couplers. At faster speeds, around $20 \mathrm{mph}$ or higher, the front end of the train crushes. When the characteristics are symmetric, no lateral movement occurs in the train.

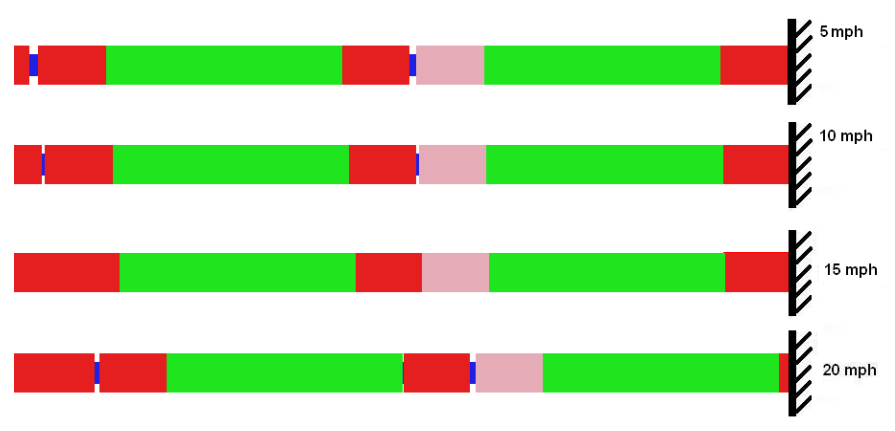

Figure 23. Modes of deformation for different initial speeds, in-line loading, and symmetric transition structure characteristics

To initiate lateral motion, an offset load is applied to the train. Rotating the coupler 2.5 degrees offsets the force between the cab car and the first coach car. By rotating the coupler, different modes are seen. When the load was applied symmetrically to the non-symmetric structure, no lateral motion was seen in any of the cars or in the couplers. This is an idealized scenario where everything is initially in-line, including the initial load from the wall and the couplers.

In the first example, shown in Figure 24, the coupler between the cab and the coach car is rotated counter clockwise 2.5 degrees about the vertical axis. This initial offset causes the cars to saw-tooth buckle. In addition to saw-tooth buckling, some of the transition structures crush. The front car crushes approximately half a foot at each characteristic, front and back, left and right. The coach car also sees some crushing at the transition structures. The front ends of the cars do not crush. In addition, there are high forces in the trucks. All of the trucks, including the trucks in the locomotive, hit the lateral force limit for derailment.

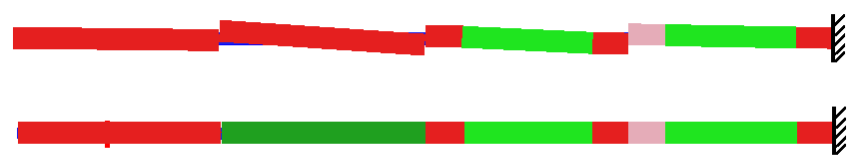

Figure 24. Out-of-line loading condition (top), in-line loading condition (bottom)

The accelerations for this case are much different, particularly in the lateral direction. The accelerations are taken at the center of gravity of the car. The lateral accelerations would be even greater at the ends of the car, where there was significant lateral movement due to the yaw of the car. Figure 25 shows the accelerations for a 15-mph collision with an offset coupler. The lateral accelerations reach values near $30 \mathrm{Gs}$, due to saw-tooth buckling. The longitudinal acceleration reaches 
over 20 Gs. This acceleration is higher than the acceleration in the non-symmetric characteristic case.
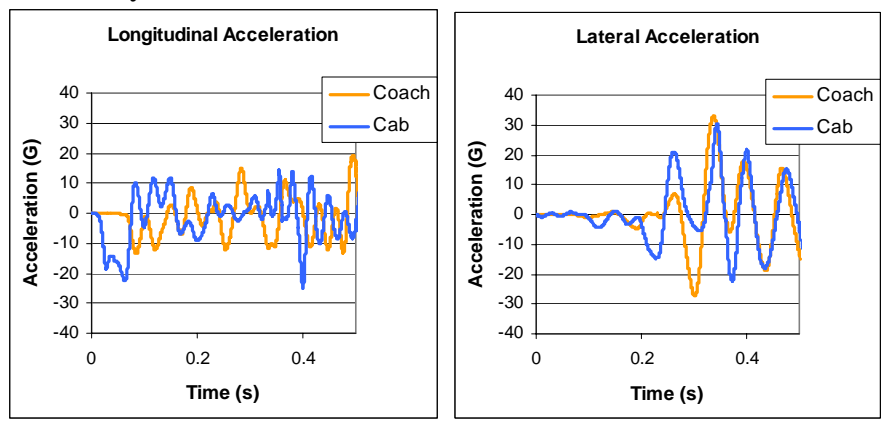

Figure 25. Acceleration traces in the longitudinal and lateral directions for a 15-mph collision

\section{SUMMARY AND CONCLUSIONS}

A full train collision dynamics model was developed to simulate a multi-level train in a collision with a wall. The model simulates three-dimensional rigid body motion, forcecrush characteristics at the front end and the transition structures, couplers and car-to-car interactions.

Non-symmetric transition structures promote saw-tooth buckling at relatively low speeds. The non-symmetric transition structures tend to crush small amounts at low speeds. The small amount of crush is uneven due to the characteristics, and the slight lateral movement leads to saw-tooth buckling. Saw-tooth buckling between cars is undesirable since it can lead to derailment.

Symmetric transition structures are more stable than nonsymmetric transition structures but are unstable under out-ofline loading conditions. Symmetric transition structure characteristics do not buckle at the transition structures. If they crush at the transition structures at all, they crush an equal amount on either side. Since the crushing occurs in-line, the cars tend to stay in-line. If an out-of-line load is applied to the car, all the cars in the train saw-tooth buckle.

Couplers play an enormous roll in determining modes of deformation, especially in regards to saw-tooth buckling. If the couplers buckle, then the cars saw-tooth buckle, and the end frames come together at an angle. This angle further amplifies the saw-tooth buckling.

For this paper a range of parameters were tested in attempts to recreate the mode of deformation seen in the collision in Placentia, CA. No combination of parameters showed the back transition structure of the cab car as a likely location to initiate a buckling mode. These results suggest that conditions in the Placentia collision were unusual. The exact orientations of the cars and the positions of the couplers at the time of the collision are unknown. There are indications that the back truck of the cab car was stuck on the rails at a grade crossing. This may have stunted longitudinal movement of the truck.

This investigation indicates that the mode of deformation for multi-level cars is likely to be similar to that of single level cars. While there have been full-scale tests on single level cars, multi-level cars have not yet been full-scale tested. More precise information, such as force-crush characteristics for the front end and the transition structure, would resolve the issue of correct structural response. Multi-level cars with crash energy management (CEM) crush zones would ensure that crush occurs only at the ends of the cars.

\section{ACKNOWLEDGEMENTS}

This work was performed as part of the Equipment Safety Research Program sponsored by FRA's Office of Research and Development. The authors would like to thank Tom Tsai, Program Manager, and Claire Orth, Division Chief, Equipment and Operating Practices Research Division, Office of Research and Development, FRA, for their support.

\section{REFERENCES}

1. Priante, M., “A Collision Dynamics Model of a Bi-Level Car,” Tufts University Master's Thesis, May 2006.

2. Tyrell, D., "Passenger Rail Train-to-Train Impact Test Volume I: Overview and Selected Results,” U.S. Department of Transportation, DOT/FRA/ORD-03/17.I, July 2003.

3. Parent, D., Tyrell, D., Perlman, A.B., “Crashworthiness Analysis of the Placentia, CA Rail Collision,” Proceedings of ICrash 2004, International Crashworthiness Conference, San Francisco, California, July 14-16, 2004.

4. National Transportation Safety Board. 2003. Collision of Burlington Northern Santa Fe Freight Train with Metrolink Passenger Train Placentia, California, April 23, 2002. Railroad Accident Report NTSB/RAR-03/04, Washington, DC.

5. Tyrell, D.C., Perlman, A.B., "Evaluation of Rail Passenger Equipment Crashworthiness Strategies,” Transportation Research Record No. 1825, pp. 8-14, National Academy Press, 2003.

6. Tong, P., “Mechanics of Train Collision,” 1976, Final Report FRA-OR\&D-76-246, Cambridge, Massachusetts.

7. Severson, K., “Development of Collision Dynamics Models to Estimate the Results of Full-Scale Rail Vehicle Impact Tests,” Tufts University Master's Thesis, November 2000.

8. Jacobsen, K., Tyrell, D., Perlman, A.B., "Impact Tests of Crash Energy Management Passenger Rail Cars: Analysis and Structural Measurements,” American Society of Mechanical Engineers, Paper No. IMECE2004-61252, November 2004.

9. Martinez, E., Zolock, J., Tyrell, D., “Crush Analyses of Multi-Level Equipment,” American Society of Mechanical Engineers, Paper No. IMECE2006-13214, November 2006. 